\title{
Reflexão acerca da bioética: um estudo de caso empírico
}

\section{[Reflections concerning bioethics: a study regarding to an empirical case ]}

\author{
Ermano Rodrigues do Nascimento*
}

\begin{abstract}
Resumo
O presente texto faz uma reflexão acerca da educação e da saúde no Nordeste brasileiro, à luz da Bioética, considerando essenciais as políticas públicas em prol da sociedade civil, mas também, priorizando a formação intelectual e moral dos profissionais de saúde como Agente Comunitário de Saúde (ACS) e o Enfermeiro. Neste contexto, o olhar da Bioética nos leva a analisar se os procedimentos e as aplicabilidades das políticas públicas pelos gestores públicos condizem com a realidade do povo nordestino. Constatamos que falta muito caminho a percorrer e que tudo depende de vontade política em direcionar o bem público à população de forma igualitário e/ou equitativa para se consegui qualidade de vida com justiça e dignidade humana. Para tanto, se faz jus respeitar a vontade popular quanto aos seus direitos e deveres na formação de uma consciência crítica cidadã e democrática na promoção do ser humano.
\end{abstract}

Palavras-chave: Educação; Saúde; Bioética, Políticas Públicas; Dignidade Humana.

\begin{abstract}
This text makes a reflection concerning education and health, in the brasilian northestm in a view of bioethics, considering as essential the public politics, in favour of the Civil Society, as well as while one prioritizes the healthy profissionals. In this context, the bioethics view leads one toward analysing whether the public politics proceedings and applicabilities, by the public managers, are in agreement with the northeastern peaple reality.
\end{abstract}

Key-words: Education; Health; Bioethics; Public Politics; Human Dignity.

\section{Introdução}

Olhar a Educação e a Saúde no Nordeste brasileiro é, realmente, uma questão de Saúde Pública que requer uma leitura

\footnotetext{
* Doutor em Educação. Professor do departamento de de teologia da UNICAP.
} 
Bioética. A realidade do Nordeste brasileiro quanto à formação intelectual do Agente Comunitário de Saúde da Família e do Enfermeiro merece uma discussão tendo em vista a atividade desses profissionais. Portanto, merece destaque a cidade do Recife como referencial para o Nordeste brasileiro. Apresentamos alguns aspectos fundamentais dessas atividades de forma que se possa ter uma melhor visão e entendimento dos desafios que hoje enfrentamos com relação à saúde e à educação na sociedade.

\section{Olhando a Realidade}

A realidade da qual nos deparamos hoje em dia quanto à educação e à saúde no Nordeste brasileiro mostra-nos a demasiada precariedade nas duas áreas causando impactos gritantes e até mesmo assustadores. Em primeiro lugar, referente à educação, não há uma preocupação em intelectualizar através de uma educação continuada e integral. Em segundo, é crescente o número dos semianalfabetos e dos analfabetos funcionais. Terceiro, a preocupação dos Estados e Municípios é com a escolarização onde se informa, mas não forma a consciência cidadã e democrática crítica. Para isso é praticamente proibido a reprovação. Logo, denota-se uma educação fraca e sem qualidade. Alunos desinteressados e sem motivações e mais, o ensino nas escolas é fraco e sem investimento adequado levando o alunado a desistência e a um fracasso escolar considerável.

Problemas familiares são fortemente destacados nas situações diárias nas escolas desde a violência doméstica ao mundo das drogas. Contudo, ainda se constata um analfabetismo intolerável.

Segundo o SINTEPE, a estatística geral do Brasil mostra o Estado de Pernambuco entre os dez priores índice de analfabetismo como: o Nordeste ainda figura como a região com o maior número de analfabeto do Brasil. Pernambuco ocupa a oitava pior colocação no ranking. O Brasil com 14.612.183 de analfabetos. Pernambuco, paga o pior salário dos professores da educação básica. Tem $16,73 \%$ dos analfabetos brasileiros (Cf. http://www.sintepe.org.br/site/v1/index.php/component/content/arti cle/40-noticias/1394-analfabetismo).

Quanto a área da saúde podemos destacar o Estado de 
Pernambuco com mais de 13 mil médicos e menos de 3 mil médicos estão nas cidades do interior e mais de 10 mil estão na capital proporcionando um desequilíbrio no trato e cuidado para com o ser humano. Verônica Almeida afirma que Recife é a quinta capital com maior número de médicos,

Pesquisa divulgada pelo Conselho Federal de Medicina (CFM). A capital pernambucana tem 6,27 médicos registrados no conselho médico para cada mil habitantes. Está acima do Rio de Janeiro (sexto lugar) e até mesmo de São Paulo (décimo primeiro). O principal polo médico do País e também cidade mais populosa tem 4,48 profissionais por cada mil moradores. A Demografia Médica no Brasil mostrou que a média brasileira é de dois médicos por mil habitantes. Pernambuco fica em $11^{\circ}$ lugar, com 1,57 médicos por mil habitantes, abaixo da média nacional, mas em primeiro lugar no Nordeste. O levantamento revela que ainda persiste a desigualdade regional e uma concentração nas grandes metrópoles, prejudicando a população do interior.(http://jc.ne10.uol.com.br/blogs/maissaude/20 13/02/18/recife-e-a-quinta-capital-com-maiornumero-de-medicos/).

Por parte da União os projetos e/ou programas de políticas públicas de caráter social para com a educação e a saúde são muitos, mas não atingindo satisfatoriamente ao apelo popular que, por sua vez, reivindica profissionais qualificados tanto na educação quanto na saúde do ponto de vista intelectual e cientifico, considerando também as baixas remunerações percebidas por esses profissionais. É de se levar em consideração que a maioria dos alunos nas escolas públicas é pobre e a escola é o lugar onde recebe, principalmente, alimento, isto é, a merenda escolar que para muitos alunos se torna a refeição do dia. Os pais devem se responsabilizar pela presença dos filhos na escola e, assim devem sempre incentivá-los para poder receber a "bolsa escola" que vai de acordo o número de filhos, pois esta se torna uma renda a mais na família.

Quanto à saúde, há cidades nos interiores do Estado (agreste 
e sertão) onde não há médicos, enfermeiros nem agentes de saúde. São regiões totalmente desassistidas e foi a partir dessa realidade que o Governo Federal motivou e criou o programa "Mais Médico" incentivando a vinda de médicos de outros países para trabalharem pelos agrestes e sertões dos Estados nordestinos despertando uma crítica por parte dos médicos locais.

\section{O legado cultural e a criação do SUS}

Não obstante, o Nordeste brasileiro é uma região "sui generis". Há uma riqueza cultural imbuída em suas raízes de origem indígena e mesclada com outros povos advindos de um processo antropológico, sociológico e religioso do mundo europeu e do mundo africano. Assim, o indígena ou aborígine que aqui vivia e, que com a chegada das novas culturas deram a esses povos os alicerces de um patrimônio cultural vivo e rico de valores humanísticos que até hoje paira sobre o ar nordestino sedimentando a cultura pelo seu estilo e/ou modo de vida de um povo muito hospitaleiro e solidário, alegre e festivo.

Contudo, diante da pobreza e da miséria de um povo caracterizado como doente e com pouca escolaridade teve e tem de enfrentar muitos desafios preconceituosos e discriminatórios. Por sua vez, o Brasil instituiu um Sistema Único de Saúde (SUS) em 1990. Oficialmente a sociedade foi recebendo uma assistência na saúde, mesmo que precária, mas que estava consignada na legislação oficial. Esse acompanhamento trouxe às pessoas melhores perspectivas e qualidade de vida a partir da saúde. A população brasileira cresceu significativamente e olhando a sua própria história verificamos que em 1918 a população rural, de todo o Brasil, era de vinte milhões de pessoas; havia dezessete milhões de enfraquecidos pelos parasitas, três milhões de vítimas da doença de Chagas, dez milhões de atacados pela malária e ainda cinco milhões de tuberculosos (Cf. BERTOLLI FILHO, 2008, p. 21). Outro dado agravante era quanto à qualidade de vida dos brasileiros, principalmente dos nordestinos que

No final da década de 50, naquele período a esperança média de vida de um brasileiro era de 51 anos em Porto Alegre, 49 em Belém e 37 em Recife. (...) No interior a questão era ainda pior: calculava-se que o 
habitante do sertão nordestino viveria em torno de trinta anos - média de vida da população européia no momento mais crítico da Idade Média. (Ibidem, p. 42).

Ao salientarmos que o Nordeste brasileiro tem uma riqueza cultural, histórica e economicamente sustentável, não implica afirmar que os desafios não continuam, pelo contrário, aumentaram tendo em vista que a população também cresceu e, é nesse contexto que percebermos outros vieses que não são da sua expansão territorial, mas, sobretudo, social e político e, ainda, recebem influências do mundo globalizado economicamente. Contudo, as implicações éticas surgem com frequencia, porque a riqueza estivera concentrada nos fazendeiros ou coronéis (donos dos latifúndios) e atualmente está sobre o domínio das multinacionais.

A questão principal continua sendo um domínio da cultura pelo econômico descaracterizando em parte sua originalidade. Por outro lado, quando se trata da saúde e da educação no Nordeste, é de suma importância fazer essa relação com esse universo cultural globalizado, pois o mesmo influencia nas políticas públicas no que toca a uma saúde de qualidade e a uma educação eficiente. Nessas situações estão imersos os profissionais de saúde que podem ou não utilizar novas tecnologias, em sua maioria não dispõem de recursos para tal, pois não encontram políticas de suporte, principalmente, econômico que favoreçam as melhorias nos ambientes de trabalho já que hoje o desenvolvimento econômico globalizado exige expansão de sua produção e para isso é necessário investimento.

\section{Influência da globalização}

Como a globalização penetra nos povos buscando fortalecer-se economicamente, as culturas sofrem o poder da exploração subjacente a esta realidade econômica. Não é diferente no Nordeste brasileiro, apesar do povo alimentar seus desejos, seus anseios subjacentes na busca de melhores condições de vida. $\mathrm{O}$ nordestino vive na dicotomia das contradições entre a riqueza e a pobreza, o luxo e a miséria, o supérfluo e a falta, o saber e a ignorância que desencadeiam, sobretudo, numa sociedade onde os horizontes da esperança e da certeza permeiam a labuta do cidadão marcado por sua integridade, firmeza e rudeza de espírito, de índole 
e caráter fortemente atingidos pelas intempéries do clima com suas secas devastadoras e uma vida de sacrifícios e sofrimentos. Mas, tudo isso é envolvido pelo modelo capitalista globalizado.

Nesse contexto, a globalização torna-se um estímulo no comodismo e na acomodação nas pessoas implantados pelos projetos políticos assistencialistas e paternalistas para a manutenção de uma injustiça social radical ao longo dos séculos na história dessa região.

Por isso, percebemos questões éticas bem pertinentes às várias formas como os profissionais atendem a população (fazendo distinções de pessoas) como também as implicações éticas e políticas na viabilização dos projetos que são criados para beneficiar ou não o povo.

\section{O papel da mulher no cuidar e no educar para a liberdade}

No Nordeste onde se luta tanto por uma igualdade ou equidade de direitos e de deveres entre homens e mulheres, tem sido uma verdadeira contenda, pois parece não haver compreensão da terminologia em discussão; Jacques Derrida salienta que "a equidade não é igualdade" (2003, p. 36), mas nem isso se pode afirmar que existe, na verdade existe uma desigualdade muito grande entre as pessoas. É diante de tal contexto e, que não se tem um denominador comum. Contudo, há uma dimensão feminina do cuidado enraizada na cultura no sentido do cuidar ético e do cuidar moral que ainda é bem presente, pois essa relação se estabelece entre "a pessoa que cuida e a pessoa que é cuidada" (Ibidem, p. 267). É pela condição dos sentimentos humanos que prevalece a visão feminina como a condição primeira para que haja afetivamente a passagem de sentimentos e de valores ético-morais na formação básica do indivíduo, naturalmente quebrada pela globalização.

Como a cultura não pode distanciar-se de um projeto de educação e de uma formação humana centrada no desenvolvimento integral do ser humano, também não é possível existir uma escola que não caminhe inserida à realidade do homem como sendo ele o próprio sujeito da educação onde a escola possa ser o espaço fundamental na formação da consciência crítica e democrática. Foi nessa perspectiva que surgiu o educador Paulo Freire, natural de 
Recife, Pernambuco, o qual teve a ideia de sistematizar um método de educação para alfabetizar jovens e adultos. a partir de uma estrutura dialógica entre o professor, o aluno e a realidade ou o quotidiano em que está inserido o próprio aluno. Uma "Educação para a Liberdade" ou uma "Pedagogia do Oprimido" como diz o próprio Paulo Freire, com o despertar da consciência, conduzindo-a a criticidade do pensamento para viver a praticidade do cotidiano.

Nesse processo torna-se fundamental o conhecimento empírico essencialmente baseado na vida e, assim fazer com que o próprio aluno sinta-se e perceba-se agente e construtor do conhecimento e da própria história a partir de uma concepção problematizadora onde o aluno "é o sujeito que se deve autoconfigurar responsavelmente" (1987, p. 9).

A escola não é vista e creditada como o lugar agradável, accessível e de comprometimento com toda a sociedade de forma responsável. Não é entendida como o lugar onde o exercício da vida cidadã começa de forma crítica, já que se trata de uma sociedade democrática de direitos como é o Brasil.

Diante dessa realidade, podemos dizer que a escola ainda está longe de chegar a atingir esse espaço privilegiado da construção do saber e da permuta das experiências feitas no quotidiano dos seus componentes e onde essa experiência acontece. Não há persistência nem consistência e, se há, torna-se fato isolado. As prioridades nas escolas não passam pelas preocupações com a aprendizagem, limitando-se muitas vezes a números.

A princípio o bem-estar social deverá ser prioridade dos planos de governo e, assim, refleti-los. A formação humana visando à equidade social por melhores condições de vida deve ser uma bandeira social hasteada constantemente lado a lado com a educação e a saúde integrando-se na construção e concretização de uma nova sociedade.

\section{Políticas públicas ao nível de Brasil, Pernambuco e Recife}

O governo tem, portanto, um total de 64 programas dentro das políticas públicas, especificamente no âmbito da educação. No entanto, para desenvolver melhor esse programa, o Plano de Desenvolvimento Escolar (PDE) apresenta como possibilidades de crescimento investir também nos meios que possibilitam esse 
desenvolvimento com as seguintes ações: Índice de Qualidade, Provinha Brasil, Transporte Escolar, Gosto de Ler, Brasil Alfabetizado, Luz para Todos, Formação, Educação Superior, Acesso Facilitado, Biblioteca na Escola, Educação Profissional, Estágio, Proinfância, Salas Multifuncionais, Pós-Doutorado, Censo pela Internet, Saúde nas Escolas, Olhar Brasil, Mais Educação, Educação Especial, Professor-Equivalente, Guia de Tecnologia, Coleção Educadores, Dinheiro na Escola, Concurso, Acessibilidade, Cidades-Pólos e Inclusão Digital. (MEC, 2007).

Salientamos, portanto, que entre as políticas públicas para a educação existe, também, um programa específico para a saúde escolar. O Programa Nacional de Saúde Escolar (PNSE), criado em 1984 pelo Governo Federal tem como princípio atender as necessidades de saúde da população escolar, principalmente, no que se refere à identificação e correção precoce das dificuldades visual e auditiva dos alunos. Em 1995 houve uma reformulação no programa, a partir do Programa Comunidade Solidária que, por sua vez, criou dois projetos: o Projeto Cesta Saúde do Escolar (PCSE), visando adotar a escola de produtos de higiene pessoal e de primeiros socorros, como também de equipamentos corretivos (visual, auditivo, etc.); o Programa Brasil Sorridente (PBS) para cuidar da saúde bucal do povo brasileiro, cuja situação principalmente a de adolescentes, adultos e idosos está entre as piores do mundo, e o Projeto de Assistência Integral à Saúde do Escolar (PAISE) para atendimento dos alunos de $1^{\circ}$ ano do ensino fundamental, que residem em bolsões de pobreza das capitais.

O Plano Estadual, por sua vez, segue as orientações básicas dos ministérios e seus programas para viabilizá-los, porém, é através de assessorias constituídas pelas Secretarias dos Estados que o gestor público (neste caso o governador) desenvolve seus projetos a nível estadual encaminhando-os como orientação necessária aos planos dos municípios. Os Municípios, também, são assessorados pelas secretarias locais fazendo com que os prefeitos cumpram o mandato seguindo as orientações determinadas pela União e o Estado do qual fazem parte, em prol do bem comum.

O Recife tem apresentado um desenvolvimento razoável procurando realizar os programas propostos, porém com morosidade. Entretanto, é a partir do Programa Bolsa Escola (PBE) que se exige a presença da criança na escola e para que saia das

50 • Universidade Católica de Pernambuco 
ruas. Por outro lado, o Programa Saúde da Família (PSF), formado por uma equipe de agentes da saúde da família procura acompanhar, sistematicamente, as famílias nos bairros. O serviço de Unidade Pronto Atendimento (UPA) atua nos casos das emergências. O Serviço de Atendimento Móvel de Urgência (SAMU) tem se ampliado mediante a demanda da situação popular e o Corpo de Bombeiros (CB) que presta serviço emergencial à sociedade. O Recife, em 2001, criou a primeira Secretaria de Saneamento (SESAN) municipal do Brasil.

Diante do que já apresentamos como desafios na educação e na saúde, vale salientar que buscamos perceber o viés que integra essas duas realidades mediante uma sociedade em transição como a brasileira. No Nordeste, já destacamos que educação e saúde estão na ponta do iceberg como desafio. Educação e saúde não têm recebido a devida atenção por parte dos gestores públicos e estão sempre sendo colocados em termos de áreas desafiadoras, mas permanecem periféricas. Como falar de integração nessas áreas se até o presente momento não têm sido verdadeiras prioridades?

\section{6. Ética, bioética, educação e saúde}

As questões voltadas à ética, à bioética, à educação e à saúde, principalmente, à saúde pública são pontos-chave da nossa reflexão que impulsionaram a realização deste estudo. Os tipos de problemas a serem investigados nesta pesquisa nos colocaram diante de um grande desafio: estudar e analisar criticamente essa problemática ética da educação e das políticas de saúde pública no Nordeste brasileiro por se tratar de uma região repleta de desafios bastantes críticos face à situação depauperada em que vive o homem nordestino.

A visão ética, a formação humana e a saúde pública passam a ser o objeto fundamental do estudo aqui exposto. A preocupação com a formação do profissional da saúde e as políticas públicas de saúde está articulada com problemáticas éticas. Para melhor compreender tal contexto, procurando conhecer melhor a situação e/ou realidade sócio, política, econômica e cultural.

Mediante tais problemáticas destacamos algumas linhas norteadoras que nos conduz a uma reflexão mais próxima da realidade, principalmente, dos profissionais da saúde e, nesse caso, 
destacamos o ACS (agente comunitário de saúde da família) e o enfermeiro tendo em vista a:

- Dimensão da formação do processo formativo;

- Dimensão da atuação profissional;

- Dimensão da satisfação: expectativa e resultado da assistência;

- Dimensão da motivação: dos elementos motivacionais.

Assim, nos depararmos com uma realidade bastante desafiadora e complexa nas áreas da saúde e da educação no Nordeste brasileiro. É preciso focar esta reflexão ou analisar a formação e a prática a partir do ACS e do enfermeiro na cidade do Recife. Nesse entendimento Veiga-Neto afirma que o que interessa é investigar uma suposta metafísica da realidade; o que interessa é o sentido que damos ao mundo (Cf. 2002, p. 32).

Para melhor conduzir tal procedimento seguimos a observar o terreno com a expectativa de melhor constatar a realidade como ela é e como se apresenta em seu cotidiano. Seguimos os quatro pontos norteadores básicos e ao observarmos tal realidade podemos constatar que a bioética é fundamental para estabelecer uma reflexão analítico-crítica tendo em vista educação e saúde, formação e prática profissional daqueles que estão diretamente inseridos na sociedade lutando pela promoção do ser humano.

Observamos que as dimensões acima oferecem possibilidades de análise abrindo um leque imenso para uma reflexão ético-bioética riquíssima e, nesse sentido destacamos de alguns aspectos fundamentais como:

- Na Dimensão da formação: Para o ACS predominam o primado da experiência, o processo contínuo cognitivo, desafia a experiência e a relação dialógica.

- Na Dimensão da satisfação: O espírito de colaboração, impasse na satisfação, papel dos gestores públicos e a consciência crítica.

- Na Dimensão da atuação: A relação subjetiva e prática, abertura para comunicação, aprender a escutar, integração entre formação, saúde e trabalho.

- Na Dimensão da motivação: O calor humano, a liberdade, a ética e espírito crítico.

Percebemos quanto à formação e a prática do ACS transita 
numa relação de autêntica colaboração e consegue fazer uma ponte dos valores estabelecidos dessa relação tendo em vista não perder o foco da sua formação nem do trabalho desenvolvido dentro da comunidade local.

Destacamos também que os quatro aspectos interagem entre si valores humanos que tramitam no próprio espírito humano numa dimensão dialógica de busca de mudanças e transformações pessoais e sociais. Hoje, segundo Barros, "a convivência de diferentes modelos teóricos que sustentam as práxis educativas no setor da saúde é marcante" (2006, p. 27). Portanto, a educação em saúde requer que seja dada ênfase ao trajeto da formação pedagógica do indivíduo no objetivo de realizar um "trabalho de transmissão de conhecimento para a mudança de comportamento" (Ibidem).

Ao observarmos tal contexto pudemos perceber os seguintes destaques no:

- Ambiente de trabalho: Caráter emergencial e preventivo; simples e pequeno; atendimento domiciliar e identificação pessoal. - Na comunicação no ambiente de trabalho: Verdadeira; funcional; prática; simples; objetiva e direta.

- Na organização institucional: Controle gerencial; diversidade de funções; precariedades e limitações; controle das atividades; colaborar, ajudar e cuidar.

- O trabalho do agente comunitário de saúde: Atividade diária; maturidade; conhecimento básico; senso crítico; obrigatoriedade; cumprimento das tarefas; conhecimento aplicado; habilidade e percepção.

Todos esses valores são expressos a partir da atuação do trabalho em equipe num ambiente bastante exaustivo. São valores que estão presentes pelo esforço da colaboração e envolvimento de todos em prol da comunidade. É um trabalho que visa a promover a saúde e, nesse sentido, tem como objetivo alcançar "um nível ótimo de vida e saúde (...), buscando fortalecer tudo aquilo que contribui para melhoria da saúde e do desenvolvimento humano" (BARROS, 2006, p. 51). Embora percebamos que o ótimo é não ter nenhum problema de saúde nem falta do que é básico para a sobrevivência. Cabe-nos observar esse momento formativo como algo especial 
para a vida profissional dos agentes da saúde e, nesse sentido, Barros chama a atenção para que se perceba o valor na perspectiva do "entendimento de que o processo participativo é uma força social imprescindível para impulsionar mudanças, passando-se da teoria discursiva para as ações práticas e concretas" (2006, p. 33).

Eis algumas características principais da formação do enfermeiro:

- Dimensão da formação: Do enfermeiro: acadêmicaespecializada; necessidade de conteúdo teórico, ético e bioético.

- Dimensão da satisfação: Do enfermeiro: momento de realização pessoal; cuidar da saúde do outro.

- Dimensão da atuação: Do enfermeiro: muito trabalho para atender em tempo hábil; falta maior atenção dos órgãos competentes.

- Dimensão da motivação: Do enfermeiro: gosto pelo trabalho, ajudar; sentido para viver, colaborar.

Manter um profissional da saúde bem motivado significa ter qualidade no atendimento ao público. As pessoas precisam de atenção e compreensão, principalmente quando se está doente. Portanto, o profissional da saúde deve receber todo o apoio necessário para lidar com eficiência e desvelo na profissão.

Esses valores são expressos a partir da atuação do trabalho em equipe num trabalho bastante exaustivo. São valores que estão presentes pelo esforço da colaboração e envolvimento de todos em prol da comunidade onde está inserido o enfermeiro. É um trabalho que visa a promover a saúde e, nesse sentido, tem como objetivo alcançar "um nível ótimo de vida e saúde (...), buscando fortalecer tudo aquilo que contribui para melhoria da saúde e do desenvolvimento humano" (BARROS, 2006, p. 51).

Mediante o quadro acima apresentado envolvendo a prática do ACS e do enfermeiro, vale salientar que uma questão é evidente e comprometedora, isto é, qual o sentido e o significado das preocupações éticas, num contexto nordestino onde se cruzam a saúde e a educação?

A partir daí é possível destacar quatro dimensões estruturantes: a ética, a bioética, a saúde e a educação levando-se em consideração um olhar analítico-crítico sobre as políticas 
públicas e as práticas profissionais da saúde no Nordeste brasileiro envolvendo fundamentalmente o ACS e o enfermeiro que na relação utente e profissional são os mais próximos e presentes nas vidas das pessoas.

É situando-se nesse contexto desafiador que foi possível partir da concepção de que a bioética não possui novos princípios éticos fundamentais. Trata-se, todavia, da ética já conhecida e estudada ao longo da história da filosofia, porém aplicada a uma série de situações novas, causadas pelo progresso das ciências biomédicas. A realidade nordestina é carente destas problematizações. Podemos falar de uma ética aplicada e que se ocupa do uso correto das novas tecnologias na área das ciências médicas e da solução adequada dos dilemas morais por ela apresentadas (Cf. CLOTET, 2003, p. 33).

As preocupações éticas são encontradas no terreno da vida, possuem uma abrangência global. Há no questionamento ético uma dimensão interdisciplinar, virada para o cotidiano. Na generalidade da escolha dos profissionais, mesmo na área da decisão clínica, existe uma preocupação de natureza ética - há dimensões éticomorais que se identificam tanto nas políticas públicas na área da saúde e na educação como no acesso a esses bens no Nordeste brasileiro. Os profissionais de saúde surgem como importantes mediadores culturais. Disponibilizam cuidados de saúde, mas são também agentes de socialização. Confrontam-se no cotidiano com dilemas éticos, muitos dos quais pela incapacidade de prestarem os cuidados que gostariam, devido aos recursos escassos. De qualquer forma, a educação dos profissionais e da população, vista numa perspectiva local, despertar em todos os atores uma consciência crítica e um nível mais elevado de cidadania.

Há diferenças entre os cuidados disponibilizados pelo ACS e o enfermeiro no que se refere à intervenção de natureza relacional e clínica junto da população. O nível educacional da população, as características demográficas e os recursos condicionam os cuidados. Nem sempre os profissionais, com experiências importantes na área da educação e da saúde influenciam a definição das políticas públicas. Muitos acham que não vale a pena, mas também nem sempre o poder político está aberto à participação. No entanto, há uma clarividência crescente, ao assumirem que as diversas práticas de saúde se integram no sentido de uma 
assistência à saúde na realidade nordestina. Esta realidade acontece mesmo perante as dificuldades que os profissionais possuem em realizar a sua formação técnico-científica.

Contudo, a perspectiva ética, que está presente nas práticas dos profissionais de saúde, faz com que o profissional adquira um autocontrole e autodomínio sobre suas ações, mesmo perante condições adversas. Poder-se-ia dizer que para muitos profissionais não se trata só de uma profissão, mas de uma vocação. A formação em saúde tem preparado o profissional da saúde para exercer com coerência sua profissão, respeitando aspectos científicos, técnicos e instrumentais. Mas as questões éticas e antropológicas também ganham espaço, principalmente quando se pensa como agir e como agir bem; como lidar com o doente, principalmente, em estágio terminal ou com doenças muito graves.

Diante do contexto apresentado é possível destacar alguns pontos que parecem relevantes para se promover uma mudança na saúde pública. Segundo Tarride, para a promoção da saúde pública são importantes três vertentes: a) a saúde pública deverá ser mudada através de um repensar a saúde; repensar os referentes sociais; um repensar ideológico; um repensar o trabalho; repensar os valores, a solidariedade; ampliar enfoques e métodos; atender ao contexto e à complexidade; melhorar os treinamentos e revisar a epistemologia. b) a saúde pública deverá ser revitalizada através da mudança de algumas posições ideológicas. c) a saúde pública deverá ser promovida através da introdução de algumas modificações específicas, quer oriundas das evidências da investigação quer da especificidade cultural da sociedade. Só assim conseguiremos uma nova Saúde Pública, mais sustentável, igualitária, segura, justa, equitativa, ética e complexa (Cf. 2002, p. 42).

\section{Conclusão}

Toda e qualquer política pública que se prese tem de primar pela formação dos agentes de saúde com a melhor qualidade possível, pois o nível de responsabildade aumenta a cada dia. $\mathrm{O}$ Estado tem um compromisso social imprescindível em distribuir de forma justa os bens públicos para melhor se ter qualidade de vida. Logo, a educação, a saúde, o trabalho, o lazer, a alimentação, etc., 
são imprescindíveis para termos uma sociedade sadia e efciente. Pois, segundo Oliveira, "as concepções de saúde humana, a todas as dimensões são atribuídas importância na manutenção ininterrupta de estados de equilíbrio orgânico sempre inevitáveis" (2004, p. 29). O ser humnao carece dessa disposição para que a qulidade de vida seja fato e se possa viver justa e dignamente. Este é o grande clamor do homem nordetino, porque não se eleva uma nação com assistencialismoe e paternalismos exagerados, mais com educação e saúde.

É importante salientar que a formação profissional estabeleça processos de desenvolvimento integral e integrado dos infivíduos e das comunidades, sempre na reconversão e/ou renovação de conhecimentos. (Cf. ANTUNES, 2008, p. 95). O Nordeste brasileiro necessita de gestores públicos que voltem sua consciência e atuação em prol do bem comum de forma justa.

\section{Referências}

ANTUNES, Maria da C. P. Educação, saúde e desenvolvimento. Coimbra: Almedina, 2008.

BARROS, Cládia Márcia Santos; MARTORELLI, Rita de Cássia Gonzaga e FREITAS, Viviane Vieira. Modelo de atividade: educação em saúde. SESC, Serviço Social do Comércio, DN/DPD/GEP. 2006.

BERTOLli FILHO, Cáudio. História da Saúde Pública no Brasil. São Paulo: Ática, 2008.

CLOTET, Joaquim. Bioética: Uma aproximação. Porto Alegre: EDIPUCRS, 2003.

DERRIDA, Jacques. Força de Lei. O Fundamento Místico da Autoridade. Porto: Campos das Letras, 2003.

FREIRE, P. Pedagogia do oprimido. Rio de Janeiro: Terra e Paz, 1987.

OLIVEIRA, C. C. Auto-organizacão, educacão e saúde. Coimbra: Ariadne Editora, 2004.

TARRIDE, Mário Ivan (1998). Saúde pública: Uma complexidade anunciada. Rio de Janeiro: Fiocruz.

VEIGA-NETO, Alfredo (2002). Olhares... In Marisa Vorraber Costa (Org ${ }^{a}$ ). Caminhos investigativos: novos olhares na pesquisa em educação (pp. 23-38). Rio de Janeiro: DP\&A. 